\title{
Future of Multimorbidity Research: How Should Understanding of Multimorbidity Inform Health System Design?
}

\author{
Cynthia M. Boyd, MD, MPH, ${ }^{1}$ \\ Martin Fortin, MD, MSc, $\mathrm{CMFC}^{2}$
}

\begin{abstract}
Many people living with chronic conditions have multiple chronic conditions. Multimorbidity is defined here as the co-existence of two or more chronic conditions, where one is not necessarily more central than the others. Multimorbidity affects quality of life, ability to work and employability, disability and mortality. Currently, clinicians have limited guidance or evidence as to how to approach care decisions for such patients. Understanding how to best care and design the health system for patients with multimorbidity may lead to improvements in quality of life, utilization of healthcare, safety, morbidity and mortality. The objective of this paper is to review the implications of multimorbidity for the design of health system and to understand the research needs for this population. The consideration of people with multimorbidity is essential in the design and evaluation of health systems. Fundamentally, people with multimorbidity should receive a patient - and family-centered approach to care throughout the health system, and understanding how to deliver this type of care in effective and efficient ways is an enormous challenge, and opportunity, for clinicians, researchers, and policy makers today.
\end{abstract}

Key words: Multimorbidity, aging, chronic conditions, health system, healthcare, comorbidity.

Recommended Citation: Boyd CM, Fortin M. Future of Multimorbidity Research: How Should Understanding of Multimorbidity Inform Health System Design? Public Health Reviews. 2010;32:451-74.

\footnotetext{
${ }^{1}$ Division of Geriatric Medicine and Gerontology, Department of Medicine, Johns Hopkins University School of Medicine.

${ }^{2}$ Département de médecine de famille, Université de Sherbrooke, Québec.
}

Corresponding Author Contact Information: Cynthia M. Boyd at cyboyd@jhmi.edu; Division of Geriatric Medicine and Gerontology, Department of Medicine, Johns Hopkins University School of Medicine, 5200 Eastern Avenue, Mason F. Lord Building Center Tower, $7^{\text {th }}$ Floor, Baltimore, MD 21224-2734 USA. 


\section{INTRODUCTION}

Approximately one in four adults have two or more chronic conditions, and half of older adults have three or more chronic conditions. ${ }^{1-5}$ The prevalence of multiple chronic conditions (MCC) among individuals increases with age and is substantial among older adults, even though many people with MCC are under the age of 65 years. ${ }^{5}$ The number of individuals with MCC will increase dramatically in coming years. ${ }^{1}$ Comorbidity is increasingly recognized as a critical clinical issue in medical care, in part because it is an independent predictor of adverse outcomes, including quality of life (QOL), mortality, healthcare, disability, and complications of treatment beyond the effects of the individual conditions. ${ }^{6-22}$ Most research and clinical care has considered comorbidity from the perspective of an index condition. In the presence of multiple conditions this perspective becomes an inefficient and perhaps ineffective framework for management of all the chronic conditions of a single person, and may be equally flawed for a health system's approach to people with MCC. ${ }^{23}$ The term multimorbidity, capturing multiple, potentially interacting, medical and psychiatric conditions, may be more appropriate and more patient-centered for the older population than consideration from the perspective of a single index condition, which is the traditional approach. ${ }^{24,25}$ Currently, clinicians have limited guidance or evidence as to how to approach care decisions for such patients. ${ }^{26}$ Understanding how to best care and design the health system for patients with multimorbidity may lead to improvements in QOL, utilization of healthcare, safety, morbidity and mortality. ${ }^{27}$ The objective of this paper is to review the implications of multimorbidity for the design of health systems and to understand the research needs for this population.

\section{DEFINITIONS OF COMORBIDITY, MULTIMORBIDITY, AND COMPLEXITY}

Feinstein defined comorbidity as "any distinct additional clinical entity that has existed or may occur during the clinical course of a patient who has the index disease under study." ${ }^{28}$ By definition, this assumes that one is taking an index disease perspective, with one disease assuming a central place (Figure 1). The usefulness of a framework where one disease is considered central is not clear when considering the optimal care and health system for people with multimorbidity, unless one disease is truly dominant in terms of the care and well-being of the individual., ${ }^{4,26,29}$ 


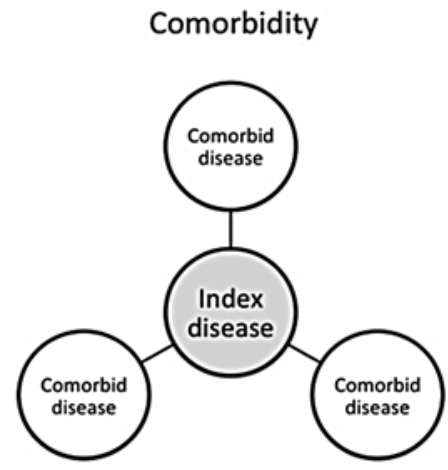

Fig. 1. Conceptual Diagram of Comorbidity: Index Disease, With One or More Comorbid Condition or Diseases Affecting Its Course and Treatment. Comorbidity has often been studied and treated in clinical practice from the perspective of an index disease, and one or more comorbid diseases may typically be considered. These diseases may affect the course and treatment of the index disease to varying degrees (varied weight of connecting bars). This framework may create disjointed treatment plans for each of the diseases and become cumbersome in patients with several co-existing diseases.

Highly prevalent chronic diseases (heart disease, diabetes, arthritis, chronic lower respiratory tract disease and stroke) are known to co-occur frequently with each other. ${ }^{30}$ Other less prevalent conditions still may occur frequently in combination with these (congestive heart failure, anemia, renal insufficiency, depression). ${ }^{31,32}$ While there are varying definitions in the medical literature, multimorbidity is defined here as the co-existence of two or more chronic conditions, where one is not necessarily more central than the others. ${ }^{4,33-35}$ Multimorbidity includes traditional diseases and syndromes but also may be extended to refer to conditions such as chronic bursitis of the hip, rotator cuff problems, dyspepsia, migraines, sleep disturbances, functional bowel syndrome or constipation, disability, falls, hearing impairment, and sarcopenia, forexample. ${ }^{34}$ The pathophysiology of these diseases, syndromes, and conditions may overlap and the management of them may interact to varying degrees. The intersection of these factors occurs in a context of biological status and physiologic reserves, as well as psychological health. The ramifications of suffering from multimorbidity unfold for a person within social, educational, cultural, behavioral, economic and environmental circumstances, which in turn affect management. While considering all of these dimensions is essential for patient-centered care, 
the best terms for considering how all of these affect clinical decisionmaking is not known. Multimorbidity needs to be considered within the context of a person, or patient. ${ }^{25,35}$ The person with multimorbidity also has individual values and priorities for their life and healthcare, which need to be elicited and factored into treatment plans.

The failure of healthcare to systematically match patient needs to best therapeutic practices partly reflects the challenges of creating an integrated clinical plan for people with multimorbidity. ${ }^{26}$ Clinical approaches often focus on one disease at a time or may fail to take into account the interactions between the patient and healthcare system that become increasingly important as individual reserves diminish and the intricacy and intensity of healthcare increases.

\section{Multimorbidity}

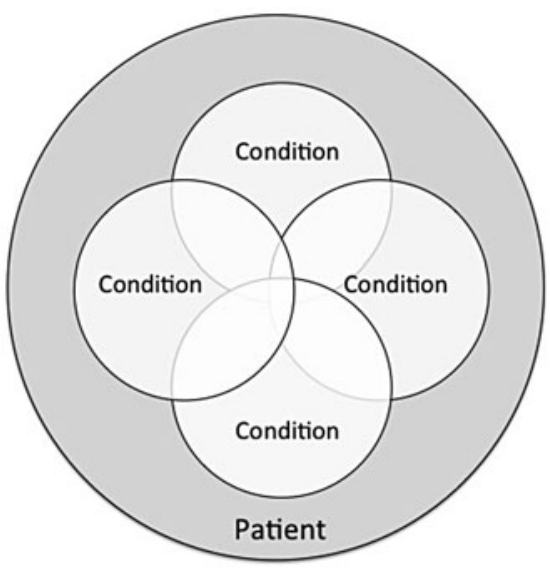

Fig. 2. Conceptual Diagram of Multimorbidity within an Individual Person's Circumstances and Preferences. The perspective of multimorbidity may be useful for treating patients with multiple conditions. Conditions include traditional diseases, but also may reflect conditions such as disability, falls, hearing impairment, and sarcopenia that fall outside the traditional disease model. These conditions may overlap to varying degrees. The intersecting conditions exist within a context of biological health and reserves, as well as the psychological circumstances of a person (i.e., positive affect). The multimorbid conditions also unfold for given people within their social, educational, cultural, economic and environmental circumstances, and these will affect management of the multimorbid conditions. The person with multimorbidity also has individual values and priorities for their life and healthcare, which need to be elicited and factored into treatment plans. 
Multimorbidity affects the clinical complexity associated with clinical decision-making and the healthcare system in which clinical decisionmaking occurs. ${ }^{31}$ Clinical complexity results from the factors or elements that should be reconciled or addressed when making decisions about a therapeutic strategy or prevention strategy. Because there is a lack of agreement on definitions of complexity and not all current definitions include non-medical dimensions, this term may be challenging. ${ }^{36}$ For people with multimorbidity, the essential element is that decisions must be made within the context of a person (see Figure 2). Some decisions may be reducible to a single decision (i.e., Will a statin benefit this patient, and is she willing and able to take it?) but more commonly they involve several clinical questions at the same time (Should a patient start a statin, antidepressant, and pursue rehabilitation?). The latter scenario implies the need for prioritization - i.e., what is most important if not everything can be done and what should be done first if everything cannot or should not be done at one time. Some co-occurring conditions may be managed synergistically (i.e., the use of ace inhibitors for diabetes and hypertension), and guidelines and quality standards sometimes recognize this overlap of clinical management. These conditions are thus concordant. ${ }^{29,37}$ Discordant conditions are more likely to add to the complexity of clinical decisionmaking. The care of people with multimorbidity is failed by approaches that do not look at more than one factor or dimension and that may rely on conventional analytic techniques. ${ }^{38}$

\section{PEOPLE WITH MULTIMORBIDITY: PREVALENCE}

The prevalence of multimorbidity increases with age, but is not just an issue for older adults. As a result of advances in medical care and public health, a growing proportion of people have multimorbidity. ${ }^{39}$ In an Australian cohort study, more than 40 percent of the people with multimorbidity were less than 60 years of age. ${ }^{40}$ The prevalence of multimorbidity is striking in studies conducted in several countries in different parts of the world. ${ }^{1-}$ 3,11,12,30,39,41-49 While the prevalence varies, this partially depends on the source of the population studied (patients vs. population based samples), sources of data (e.g., surveys, chart reviews, administrative data), data collection methods, targeted age groups, diagnoses considered and study populations, making the comparability of prevalence estimates questionable. ${ }^{3}$ The presence of multimorbidity also indicates higher risk of additional conditions; people with multimorbidity are at a higher risk of being diagnosed with two or more new diseases than those with no disease. ${ }^{14}$ 
Multimorbidity is even more important when each condition may influence the care of the other condition(s) through limitations of life expectancy, interactions between therapies, and/or direct contraindications to therapy for one condition by other conditions themselves..$^{23,25,36}$ Fortyeight percent of older adults have three or more chronic conditions. ${ }^{1}$ In younger populations, 35 percent of disabled adults have three or more chronic conditions. ${ }^{50}$ Among children, where the definition of a chronic health condition is less clear, prevalence estimates range from less than one percent up to 44 percent of children having multimorbidity. ${ }^{51}$

It can be useful to think about the prevalence of multimorbidity with varied approaches. While it is important to note how many people have multimorbidity, and which specific conditions they have, it is also worth considering reporting data in different ways. For example, among older women participating in the United States nationally representative survey NHANES, examining five major chronic diseases (coronary heart disease, stroke, diabetes mellitus, arthritis, and chronic lower respiratory tract disease) with pattern analyses reveals that less than 20 percent of people with coronary heart disease have that disease alone, and not one of the other four conditions. Similar findings for how often the disease occurs in isolation were found for stroke, diabetes mellitus, and chronic lower respiratory tract disease (all less than 20 percent of the population with each condition, respectively). For arthritis, the prevalence of arthritis alone was 47 percent. ${ }^{30}$ These numbers would be smaller if a larger pool of conditions was considered. This work demonstrates that multimorbidity is the norm, not the exception, for many chronic diseases, and may speak to researchers, disease managers, policy makers and providers who have traditionally taken an index disease approach. Researchers have investigated whether specific conditions "cluster," or occur together at greater rates than would be expected by chance alone. ${ }^{41,52}$ Such work highlights the need to understand the underlying pathogenesis of multimorbidity, and may identify targets for preventive approaches.

\section{IMPACT OF MULTIMORBIDITY ON PEOPLE}

Multimorbidity affects QOL, ability to work and employability, disability and mortality., ${ }^{4,-22,42,53-56}$ The relationship between multimorbidity and QOL is inverse, and the relationship to specific dimensions of QOL is complex. ${ }^{56}$ Some specific chronic conditions have a stronger relationship with functional status than others, and there may be interaction between specific conditions, with the risk of disability in people with specific combinations of conditions greater than expected based on risks associated with the 
individual conditions alone. ${ }^{18,57}$ The accumulation of new chronic conditions is associated with greater disability. ${ }^{58}$

\section{PEOPLE WITH MULTIMORBIDITY AND THEIR FAMILY/SOCIAL SUPPORTS}

People living with multimorbidity have greater self-care needs. ${ }^{59-65}$ Complex older patients are especially likely to rely on and be affected by caregiver involvement in health management. ${ }^{66}$ Family involvement is a key dimension of patient-centered care and several studies substantiate its influence on adherence. ${ }^{67-72}$ Aside from their role in dementia care and inpatient settings and with children, the role of caregivers has not been well articulated in chronic care initiatives, but their role is increasingly recognized, particularly for people with multimorbidity. ${ }^{66,73-75}$ Caregivers are thus crucial to include in healthcare, public health policy initiatives, health system design, and research on people with multimorbidity. Many important questions remain unanswered in terms of how to optimally integrate caregivers to improve the health of people with multimorbidity. ${ }^{76}$

\section{PEOPLE WITH MULTIMORBIDITY AND CURRENT HEALTH SYSTEMS}

Patients with multimorbidity and complex healthcare needs often receive care that is fragmented, incomplete, inefficient, and ineffective..$^{11,23,48,77,78}$ For example, in addition to associations with high costs and utilization, the risk of potentially avoidable inpatient admissions or preventable complications in an inpatient setting increases dramatically with the number of chronic conditions among older adults. ${ }^{48,49}$ Patients with multimorbidity may be particularly susceptible to the hazards of hospitalization, polypharmacy, and post-operative complications. ${ }^{79-81}$

\section{HOW SHOULD AN UNDERSTANDING OF MULTIMORBIDITY INFORM HEALTH SYSTEM DESIGN?}

An essential element of health system design that addresses people with multimorbidity is the elimination of the single disease focus. We want to take care of people with multimorbidity, not the individual conditions that add up to multimorbidity. Assuming that an additive process of the single disease approach will meet the needs of people with multimorbidity is flawed and 
may even be harmful in many instances. Our health system should focus on people with multimorbidity, and recognize that some of the issues we must address are consequences of the multimorbidity and not diseases per se, but may have further adverse effects themselves. For example, polypharmacy is associated with greater rates of adverse events and drug interactions. Falls are most often multi-factorial in etiology, and yet can have dramatic impact on patient important outcomes like function and independence. For both of these examples, evidence-based interventions have been shown to improve patient important outcomes, and yet, neither is considered a "disease". ${ }^{22,83}$ Throughout healthcare, the disease-based focus prevails, from the design of clinical trials to the reimbursement structure in many countries. ${ }^{84}$

\section{The Chronic Care Model}

The Chronic Care Model (Figure 3), as described by Wagner et al., provides many of the essential elements of a healthcare system optimally designed for people with MCC. ${ }^{85}$ It is important to view this model and how it applies from the perspective of multimorbidity, not only a single-disease focus. Many interventions that derived from this model and approach have started with a focus on single conditions, but in recent years, there have been an increasing number of interventions that recognize that most people with one chronic disease have others. ${ }^{78,86-92}$

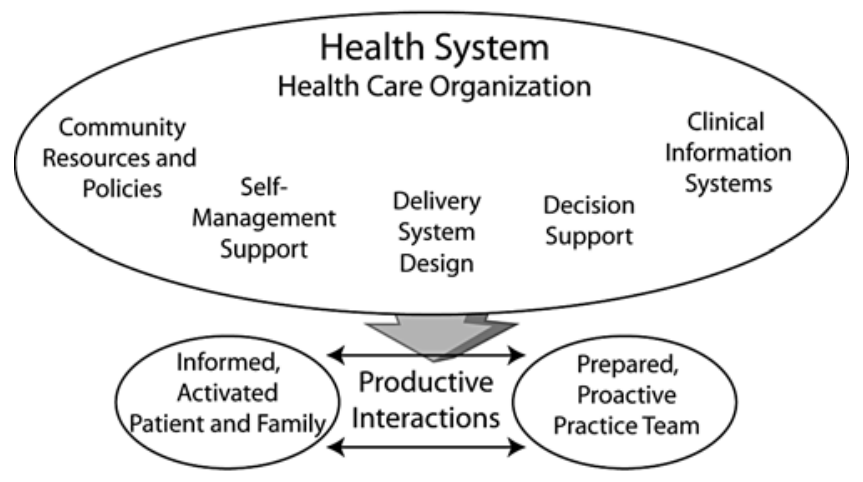

Fig. 3. The Chronic Care Model.

Source: Copyright 1996-2010 The MacColl Institute (with permission). The Improving Chronic Illness Care program is supported by The Robert Wood Johnson Foundation, with direction and technical assistance provided by Group Health's MacColl Institute for Healthcare Innovation. 


\section{Patient-Centered Care}

Primary care (or generalist care) is essential when considering how a health system should care for people with multimorbidity. Patient-centered care for patients with chronic illness is care which (1) is attentive to patient's psychosocial as well as physical needs, (2) explores the patient's concerns and priorities for care, (3) conveys a sense of partnership between the patient and physician, (4) facilitates active patient involvement in decision making, and (5) is coordinated across professionals, facilities, and support systems. ${ }^{93,94}$ This type of patient-centered care in a "medical home" may not need to be provided by a generalist or primary care provider, but should include the essential elements of a holistic approach to these patients and their healthcare and not focus inappropriately on one condition over others. ${ }^{94}$ In some instances, one condition may be dominant, or be so complex or serious that it eclipses the management of other conditions either in the short-term or over the long-term. ${ }^{29}$ As described by Piette and Kerr, examples of this would include end-stage disease, severely symptomatic, or recently diagnosed conditions. When one condition is not dominant, patient-centered care would ideally balance all of a person's conditions and allow for an integrated approach to their healthcare. This presents enormous challenges, as work by Yarnall et al. and Ostbye et al. demonstrates that a typical family practitioner in the US with a standard panel would not have adequate time in a typical day to deliver the services currently recommended for chronic disease management or preventive services. ${ }^{95,96}$ This work highlights two issues. First, the responsibility for patient education and follow-up of protocols and guidelines should be shared within an integrated healthcare system and community-based health programs to also engage physician assistants, nurse practitioners, professional and neighborhood health educators to provide education, counseling, and guidance. ${ }^{97-99}$ Second, the generation of evidence, the synthesis of evidence in guidelines, the development of quality standards, and the setting of healthcare system policy need to account for these issues, and prioritize across conditions and approaches to healthcare for those elements that are most important for improving the well-being of people with multimorbidity. ${ }^{26,96}$

\section{Sites of Care and Transitions Between Them}

People with multimorbidity are seen frequently, and in multiple sites of care, including emergency rooms, hospitals, outpatient settings, specialty clinics, nursing home and rehabilitation facilities, assisted livings, and home healthcare. People with multimorbidity are thought particularly vulnerable to suboptimal quality care. ${ }^{1,100}$ Central then to the design of care 
for these patients is the communication and connections between these traditional silos of care. Patients with multimorbidity may be most vulnerable to the adverse consequences of transitions of care, and thus the optimal health system would allow for facile communication across sites of care to avoid duplicate testing which may be harmful, allow for medication reconciliation, and transfer of essential information about allergies, medication, recent and past history, decision-making capabilities and contact information for healthcare agents (surrogates). Work on transitional care has included both disease specific approaches and those that do not focus on a particular condition. ${ }^{100-105}$ However, much of this work has focused on the transitions between the hospital and post-hospital settings, but transitions between outpatient providers may be equally important for the long-term management of people with multimorbidity.

\section{Reimbursement Structure}

Reimbursement systems are varied across countries, and often even within the same country. Therefore, we will focus on identification of general principles for reimbursement structures considering the design of health systems and people with multimorbidity.

The goals of structuring a reimbursement system include the following key issues. These are not meant to be exhaustive in terms of considering all of the goals of reimbursement systems, but rather those issues that are particularly salient to people with multimorbidity.

- To encourage providers to want to care for people with multimorbidity (as opposed to avoiding them).

- To reward the cognitive processes and shared decision-making believed very important in making thoughtful, patient-centered decisions about healthcare.

- To reward the cognitive aspects of medicine, not just procedures and technology.

- To minimize overuse and underuse of therapies and maximize appropriate use.

- To attract adequate numbers of highly qualified individuals to primary care or care of people with multimorbidity.

- To reward a patient - and family - centered approach over a disease based-approach (with incentives based largely on disease specific quality standards).

- To reward care coordination and communication between providers across sites of care, as well as with patients and families. 
It is critical that the effects of changes to reimbursement systems be rigorously evaluated, particularly in regards to the most vulnerable populations, which include those living with multimorbidity. While there are many success stories, ${ }^{106}$ there are also many examples of unintended consequences resulting from changes in how we approach the reimbursement structures for healthcare. ${ }^{107-111}$

\section{Role of Family and Friends}

While the importance of family and friends in chronic care has been increasingly recognized, the optimal ways to engage family members in the care of people with multimorbidity are not yet known, yet many of these patients are likely to be accompanied to medical visits, and many of these medical visit companions likely assume roles in the management of healthcare tasks for these people. ${ }^{66,76,112-114}$ The term "patient- and family-centered care" is increasingly used, but it is yet to be a reality in many chronic care outpatient settings. ${ }^{15,116}$

\section{Clinical Practice Guidelines}

\section{Table 1}

Summary of Review of CPGs Applicability to Older Adults with Multimorbidity

\begin{tabular}{l|c}
\hline Issue & $\begin{array}{c}\text { Number } \\
\text { of CPGs } \\
\text { addressing } \\
\text { the issue }\end{array}$ \\
\hline Quality of evidence for older adults with multimorbidity & $2 / 9$ \\
Guidance on treatment of index condition in context of single comorbid & $7 / 9$ \\
condition & $4 / 9^{* * *}$ \\
Guidance on treatment of index condition in context of multiple & $1 / 9$ \\
comorbid conditions & $7 / 9^{*}$ \\
Discussion of QOL issues & $0 / 9$ \\
Discussion of short-term vs. long-term goals & $7 / 9^{* *}$ \\
Recommendations for incorporating patient preferences & \\
\hline
\end{tabular}

* for two of these, QOL is addressed for only a single symptom 119,120

** patient preferences are discussed only in regard to end-of-life for the congestive heart failure CPG119

*** guidance given for three of these conditions is only for multiple cardiovascular conditions Source: Boyd CM, Darer J, Boult C, Fried LP, Boult L, Wu AW. Clinical practice guidelines and quality of care for older patients with multiple comorbid diseases: Implications for pay for performance. JAMA. 2005;294:716-24. ${ }^{26}$ 
The applicability of clinical practice guidelines (CPGs) to older adults with multimorbidity is limited. ${ }^{26,117,118}$ A review of nine common chronic conditions and selected primary care and specialty CPGs recommended by national or international organizations demonstrated inadequate attention to this population. ${ }^{26}$ The CPGs were abstracted by two reviewers for components relevant to the care of older patients with multimorbidity. Thus as shown in Table 1, few of the nine CPGs address these issues of high relevance for older adults, particularly those with multiple conditions, and none of the guidelines that were reviewed comprehensively addressed these issues.

Applying relevant CPGs to a hypothetical 79 year old woman with moderate severity osteoporosis, osteoarthritis, diabetes mellitus, hypertension, and chronic obstructive pulmonary disease leads to a complex and potentially harmful treatment regimen. ${ }^{26}$ Implementing CPGs for these conditions, and choosing generic, long-acting drugs with the least side effects, she would be prescribed 12 unique medications, requiring a complex regimen of 19 doses of medication per day, and 14 nonpharmacologic treatments (self-monitoring, diet, exercise, healthcare visits, and laboratory testing). There were many potential drug-condition, drugdrug, and food-drug interactions. Non-pharmacologic recommendations also contradict. This work identifies a high level of complexity, cost, and potential burden for such a treatment regimen. Complete adherence would not be feasible for many multimorbid adults, and, as shown above, the evidence for effectiveness for this patient population is often lacking. ${ }^{26}$

With rare exceptions, guidelines focus on the management of a single disease, and do not address how to optimally integrate care for individuals whose multiple problems may make guideline-recommended management of any single disease impractical, irrelevant or even harmful. ${ }^{26,121}$ The root of this problem, however, is not narrowly confined to guideline development and application, but is inherent throughout the translational path from the generation of the evidence to the synthesis of the evidence upon which guidelines depend. Recently, emphasis has been placed on the role of "pragmatic" clinical trials to guide the care of real world populations. It is essential to note that without appropriate analytic techniques to account for heterogeneity of treatment effect, the results of such trials may be misleading about whether specific patients benefit more or less from therapies than the average patient. ${ }^{122,123}$ Efforts are currently underway to increase the applicability of our evidence-base and clinical practice guidelines to people with multimorbidity. ${ }^{124,125}$ 


\section{Quality Standards}

The applicability of current CPGs is therefore poor for patients with multimorbidity. ${ }^{26}$ The translational path culminating with guideline development for patients with multimorbidity is flawed and has implications for the development and application of performance measures. Basing standards for quality of care and pay for performance on existing CPGs could lead to inappropriate judgment of the care provided to individuals with multimorbidity and could create perverse incentives that emphasize the wrong aspects of care for this population and diminish rather than improve the quality of their care. ${ }^{26}$ Defining and measuring quality of care in a patient-centered manner is essential for complex patients.

Comprehensive consideration of these issues is important for a framework for measuring performance for people with multimorbidity. Performance measurement for patients with multimorbidity has not been adequately developed. ${ }^{126}$ Importantly, most research on quality of care in people with multimorbidity has not employed simultaneous assessment of both patientreported quality of care and technical quality of care. While disease-specific performance standards are achieved in many multimorbid adults, patient reports of quality of primary care may be worse. ${ }^{127-129}$ Limited prior work suggests that these two perspectives are often poorly correlated and that patient evaluations of care are critical in understanding performance. ${ }^{130,131}$ However, existing tools do not adequately capture the needs and complexity of people with multimorbidity, and it is unknown how to best measure performance for these patients. ${ }^{132}$

Quality of care may be defined using the Institute of Medicine's six aims for healthcare: safety, effectiveness, patient-centeredness, timeliness, efficiency, and equity. ${ }^{133}$ No one has developed and employed an assessment of multimorbidity-specific quality. Assessing Care of Vulnerable Elderly (ACOVE) measures and the Patient Assessment of Chronic Illness Care have been used to measure care for people with multimorbidity, but neither capture all of the elements important for performance for people with multimorbidity. ${ }^{134}$ Measurement of this comprehensive definition of quality of care would ideally capture optimal medical decision making with treatment appropriately individualized based on preferences and a relevant evidence base, and minimize both underuse and misuse. ${ }^{29,60,126,135}$ Goals of care for individuals with multimorbidity include patient-centered care, with a well-informed patient and provider understanding his/her individualized risks and incorporating patient preferences. The goal is to avoid causing harm from adverse consequences of treatments, and to reduce morbidity and mortality without compromising function while maximizing other patient-important outcomes. 
Patients with multimorbidity are seen in multiple sites of care and by multiple providers, and measurement of performance will need to address these issues. ${ }^{136}$ Patients with multimorbidity may benefit most from processes that target the aggregate effect of multiple conditions, such as processes related to reducing polypharmacy, fall risk, and minimizing adverse drug reactions. Over time, the framework for thinking about all of a person's conditions may need to vary, to recognize that severity, prognosis and symptom burden will change. ${ }^{29}$ Also, patients with multimorbidity often choose or need to involve family or friends in their healthcare and decision-making. ${ }^{66}$

Many patients with multimorbidity receive interventions for which there is little evidence of benefit and are at high risk for adverse health events. Performance measures are available for specific conditions and are sometimes used in patients with multimorbidity in the absence of evidence that they are appropriate, and further development is needed. Many conceptual issues in performance measurement for patients with multimorbidity require further development.

\section{Approaches Specifically Using a Multimorbidity Perspective in Primary Care}

A recent review of US models of care serving older adults with multimorbidity found similarities between the programs including: comprehensive assessment, development of a comprehensive care plan that incorporates evidence-based protocols, implementation of the plan over time, proactive monitoring of the patient's clinical status and adherence to the care plan, coordination of primary care, specialty care, hospitals, emergency departments, skilled nursing facilities, other medical institutions, and community agencies, facilitation of the patient's transitions from hospitals to post-acute settings, facilitation of the patient's access to community resources, such as meals programs, handicapped-accessible transportation, adult day care centers, support groups, and exercise programs. ${ }^{77}$ Key differences between the programs reviewed include the year in which the program began, whether an established physician or new physician was involved, the type of setting where it was provided, eligibility for the program, the frequency of contact, and reimbursement structures. ${ }^{106,137-139}$ International work has identified other models with promise. ${ }^{140-143}$ Much work is needed in this area, particularly to understand the optimal health systems for younger people with multimorbidity, as well as how to transform typical primary care practices to meet these needs. In addition, little is known about how community, neighborhoods, and environments can best 
support people with multimorbidity, although information from the broader chronic disease literature is potentially informative for understanding the necessary research agenda.

\section{CONCLUSION}

The consideration of people with multimorbidity is essential in the design and evaluation of health systems. Fundamentally, people with multimorbidity should receive a patient- and family-centered approach to care throughout the health system, and understanding how to deliver this type of care in effective and efficient ways is an enormous challenge, and opportunity, for clinicians, researchers, and policy makers today.

\section{Acronyms list:}

MCC $=$ Muliple chronic condiditons

$\mathrm{QOL}=$ Quality of life

CPGs $=$ Clinical practice guidelines

\section{Terms and definitions list:}

Multimorbidity: The co-existence of two or more chronic conditions, where one is not necessarily more central than the others.

Acknowledgments: Dr. Boyd was supported by the Johns Hopkins Bayview Center for Innovative Medicine, The Robert Wood Johnson Foundation Physician Faculty Scholars Program, and the Paul Beeson Career Development Award Program (NIA K23 AG032910, AFAR, The John A. Hartford Foundation, The Atlantic Philanthropies, The Starr Foundation and an anonymous donor). Dr. Fortin was supported by the Canadian Institutes of Health Research, the Institute for Health Services and Policy Research, the Canadian Health and Services Research Foundation and the Centre de santé et de services sociaux de Chicoutimi (Applied CIHR health services and policy research chair on chronic diseases in primary care)

Conflicts of Interest: None declared.

\section{REFERENCES}

1. Anderson G, Horvath J. Chronic conditions: Making the case for ongoing care. Baltimore (MD): Partnership for Solutions; December 2002.

2. Fortin M, Bravo G, Hudon C, Vanasse A, Lapointe L. Prevalence of multimorbidity among adults seen in family practice. Ann Fam Med. 2005;3:223-8.

3. Fortin M, Hudon C, Haggerty J, Akker M, Almirall J. Prevalence estimates of multimorbidity: A comparative study of two sources. BMC Health Serv Res.10:111.

4. Fortin M, Soubhi H, Hudon C, Bayliss EA, van den Akker M. Multimorbidity's many challenges. BMJ. 2007;334:1016-7. 
5. U.S. Department of Health and Human Services. Multiple Chronic Conditions - A Strategic Framework: Optimum Health and Quality of Life for Individuals with Multiple Chronic Conditions. Washington (DC): USDoHaH; 2010.

6. McGann PE. Comorbidity in heart failure in the elderly. Clin Geriatr Med. 2000;16:631-48.

7. Patrick L, Knoefel F, Gaskowski P, Rexroth D. Medical comorbidity and rehabilitation efficiency in geriatric inpatients. J Am Geriatr Soc. 2001;49:1471-7.

8. Concato J, Horwitz RI, Feinstein AR, Elmore JG, Schiff SF. Problems of comorbidity in mortality after prostatectomy. JAMA. 1992;267:1077-82.

9. Satariano WA. Aging, comorbidity, and breast cancer survival: An epidemiologic view. Adv Exp Med Biol. 1993;330:1-11.

10. Yancik R, Havlik RJ, Wesley MN, Ries L, Long S, Rossi WK, Edwards BK. Cancer and comorbidity in older patients: A descriptive profile. Ann Epidemiol. 1996;6:399-412.

11. Gijsen R, Hoeymans N, Schellevis FG, Ruwaard D, Satariano WA, van den Bos GA. Causes and consequences of comorbidity: A review. J Clin Epidemiol. 2001;54:661-74.

12. Fillenbaum GG, Pieper CF, Cohen HJ, Cornoni-Huntley JC, Guralnik JM. Comorbidity of five chronic health conditions in elderly community residents: Determinants and impact on mortality. J Gerontol A Biol Sci Med Sci. 2000;55:M84-9.

13. McGee D, Cooper R, Liao Y, Durazo-Arvizu R. Patterns of comorbidity and mortality risk in blacks and whites. Ann Epidemiol. 1996;6:381-5.

14. Satariano WA, Ragland DR. The effect of comorbidity on 3-year survival of women with primary breast cancer. Ann Intern Med. 1994;120:104-10.

15. Yancik R, Wesley MN, Ries LA, Havlik RJ, Edwards BK, Yates JW. Effect of age and comorbidity in postmenopausal breast cancer patients aged 55 years and older. JAMA. 2001;285:885-92.

16. Yancik R, Wesley MN, Ries LA, Havlik RJ, Long S, Edwards BK, Yates JW. Comorbidity and age as predictors of risk for early mortality of male and female colon carcinoma patients: a population-based study. Cancer. 1998;82:2123-34.

17. Guralnik JM, LaCroix AZ, Abbott RD, Berkman LF, Satterfield S, Evans DA, Wallace RB. Maintaining mobility in late life. I. Demographic characteristics and chronic conditions. Am J Epidemiol. 1993;137:845-57.

18. Fried LP, Bandeen-Roche K, Kasper JD, Guralnik JM. Association of comorbidity with disability in older women: The Women's Health and Aging Study. J Clin Epidemiol. 1999;52:27-37.

19. Cornoni-Huntley JC, Foley DJ, Guralnik JM. Co-morbidity analysis: A strategy for understanding mortality, disability and use of health care facilities of older people. Int J Epidemiol. 1991;20Suppl1:S8-17. 
20. Ettinger WH, Davis MA, Neuhaus JM, Mallon KP. Long-term physical functioning in persons with knee osteoarthritis from NHANES. I: Effects of comorbid medical conditions. J Clin Epidemiol. 1994;47:809-15.

21. Verbrugge LM, Lepkowski JM, Imanaka Y. Comorbidity and its impact on disability. Milbank Q. 1989;67:450-84.

22. Fortin M, Bravo G, Hudon C, Lapointe L, Almirall J, Dubois MF, Vanasse A. Relationship between multimorbidity and health-related quality of life of patients in primary care. Qual Life Res. 2006;15:83-91.

23. Parekh AK, Barton MB. The challenge of multiple comorbidity for the US health care system. JAMA. 303:1303-4.

24. Menotti A, Mulder I, Nissinen A, Giampaoli S, Feskens EJ, Kromhout D. Prevalence of morbidity and multimorbidity in elderly male populations and their impact on 10-year all-cause mortality: The FINE study (Finland, Italy, Netherlands, Elderly). J Clin Epidemiol. 2001;54:680-6.

25. Safford MM, Allison JJ, Kiefe CI. Patient complexity: More than comorbidity. The vector model of complexity. J Gen Intern Med. 2007;22Suppl3:382-90.

26. Boyd CM, Darer J, Boult C, Fried LP, Boult L, Wu AW. Clinical practice guidelines and quality of care for older patients with multiple comorbid diseases: Implications for pay for performance. JAMA. 2005;294:716-24.

27. Grau L, Kovner C. Comorbidity, age, and hospital use among elderly Medicare patients. J Aging Health. 1991;3:352-67.

28. Feinstein AR. The pre-therapeutic classification of co-morbidity in chronic disease. J Chron Dis. 1970;23:455-68.

29. Piette JD, Kerr EA. The impact of comorbid chronic conditions on diabetes care. Diabetes Care. 2006;29:725-31.

30. Weiss CO, Boyd CM, Yu Q, Wolff JL, Leff B. Patterns of prevalent major chronic disease among older adults in the United States. JAMA. 2007;298:1160-2.

31. Boyd CM, Leff B, Wolff JL, et al. Informing Clinical Practice Guideline Development and Implementation: Prevalence of Co-existing Conditions Among Adults with Coronary Heart Disease. J Am Geriatr Soc. 2010;In Press.

32. Boyd C, Leff B, Weiss C, Wolff J, Clark R, Richards T. Full report: Clarifying multimorbidity to improve targeting and delivery of clinical services for Medicaid populations. Center for Health Care Strategies, Inc.; 2010.

33. van den Akker M, Buntinx F, Knottnerus JA. Comorbidity or multimorbidity: What's in a name? Eur J Gen Pract. 1996;2:65-70.

34. Boyd CM, Ritchie CS, Tipton EF, Studenski SA, Wieland D. From bedside to bench: Summary from the American Geriatrics Society/National Institute on Aging Research conference on comorbidity and multiple morbidity in older adults. Aging Clin Exp Res. 2008;20:181-8.

35. Valderas JM, Starfield B, Sibbald B, Salisbury C, Roland M. Defining comorbidity: Implications for understanding health and health services. Ann Fam Med. 2009;7:357-63.

36. Agency for Healthcare Research and Quality. Optimizing prevention and healthcare management for the complex patient (R21). Services DoHaH, ed., 2007. 
37. Sales AE, Tipton EF, Levine DA, Houston TK, Kim Y, Allison J, Kiefe CI. Are co-morbidities associated with guideline adherence? The MI-Plus study of Medicare patients. J Gen Intern Med. 2009;24:1205-10.

38. Boyd CM, Weiss CO, Halter J, Han KC, Ershler WB, Fried LP. Framework for evaluating disease severity measures in older adults with comorbidity. J Gerontol A Biol Sci Med Sci. 2007;62:286-95.

39. Uijen AA, van de Lisdonk EH. Multimorbidity in primary care: Prevalence and trend over the last 20 years. Eur J Gen Pract. 2008;14Suppl1:28-32.

40. Taylor AW, Price K, Gill TK, et al. Multimorbidity - not just an older person's issue. Results from an Australian biomedical study. BMC Public Health.10:718.

41. Marengoni A, Rizzuto D, Wang HX, Winblad B, Fratiglioni L. Patterns of chronic multimorbidity in the elderly population. J Am Geriatr Soc. 2009;57:225-30.

42. Marengoni A, von Strauss E, Rizzuto D, Winblad B, Fratiglioni L. The impact of chronic multimorbidity and disability on functional decline and survival in elderly persons. A community-based, longitudinal study. J Intern Med. 2009;265:288-95.

43. Marengoni A, Winblad B, Karp A, Fratiglioni L. Prevalence of chronic diseases and multimorbidity among the elderly population in Sweden. Am J Public Health. 2008;98:1198-200.

44. Metsemakers JF, Hoppener P, Knottnerus JA, Kocken RJ, Limonard CB. Computerized health information in The Netherlands: a registration network of family practices. Br J Gen Pract. 1992;42:102-6.

45. van den Akker M, Buntinx F, Metsemakers JF, Roos S, Knottnerus JA. Multimorbidity in general practice: Prevalence, incidence, and determinants of co-occurring chronic and recurrent diseases. J Clin Epidemiol. 1998;51:367-75.

46. Schellevis FG, van der Velden J, van de Lisdonk E, van Eijk JT, van Weel C. Comorbidity of chronic diseases in general practice. J Clin Epidemiol. 1993;46:469-73.

47. Fuchs Z, Blumstein T, Novikov I, Walter-Ginzburg A, Lyanders M, Gindin J, et al. Morbidity, comorbidity, and their association with disability among community-dwelling oldest-old in Israel. J Gerontol A Biol Sci Med Sci. 1998;53:M447-55.

48. Wolff JL, Starfield B, Anderson G. Prevalence, expenditures, and complications of multiple chronic conditions in the elderly. Arch Intern Med. 2002;162:2269-76.

49. Schneider KM, O’Donnell BE, Dean D. Prevalence of multiple chronic conditions in the United States' Medicare population. Health Qual Life Outcomes. 2009;7:82.

50. Kronick RG, Bella M, Gilmer TP, Somers SA. The faces of Medicaid II: Recognizing the care needs of people with multiple chronic conditions. Hamilton (NJ): Center for Health Care Strategies, Inc.; 2007.

51. van der Lee JH, Mokkink LB, Grootenhuis MA, Heymans HS, Offringa M. Definitions and measurement of chronic health conditions in childhood: A systematic review. JAMA. 2007;297:2741-51. 
52. Guralnik JM. Assessing the impact of comorbidity in the older population. Ann Epidemiol. 1996;6:376-80.

53. Fortin M, Dubois MF, Hudon C, Soubhi H, Almirall J. Multimorbidity and quality of life: A closer look. Health Qual Life Outcomes. 2007;5:52.

54. Newman AB, Boudreau RM, Naydeck BL, Fried LF, Harris TB. A physiologic index of comorbidity: Relationship to mortality and disability. J Gerontol A Biol Sci Med Sci. 2008;63:603-9.

55. Peters-Klimm F, Kunz CU, Laux G, Szecsenyi J, Muller-Tasch T. Patient - and provider-related determinants of generic and specific health-related quality of life of patients with chronic systolic heart failure in primary care: A crosssectional study. Health Qual Life Outcomes.8:98.

56. Fortin M, Lapointe L, Hudon C, Vanasse A, Ntetu AL, Maltais D. Multimorbidity and quality of life in primary care: A systematic review. Health Qual Life Outcomes. 2004;2:51.

57. Fultz NH, Ofstedal MB, Herzog AR, Wallace RB. Additive and interactive effects of comorbid physical and mental conditions on functional health. J Aging Health. 2003;15:465-81.

58. Wolff JL, Boult C, Boyd C, Anderson G. Newly reported chronic conditions and onset of functional dependency. J Am Geriatr Soc. 2005;53:851-5.

59. Bayliss EA, Bosworth HB, Noel PH, Wolff JL, Damush TM, McIver L. Supporting self-management for patients with complex medical needs: Recommendations of a working group. Chronic illness. 2007;3:167-75.

60. Bayliss EA, Edwards AE, Steiner JF, Main DS. Processes of care desired by elderly patients with multimorbidities. Fam Pract. 2008;25:287-93.

61. Bayliss EA, Ellis JL, Steiner JF. Seniors' self-reported multimorbidity captured biopsychosocial factors not incorporated into two other data-based morbidity measures. J Clin Epidemiol. 2009;62:550-7.

62. Bayliss EA, Ellis JL, Steiner JF. Barriers to self-management and quality-of-life outcomes in seniors with multimorbidities. Ann Fam Med. 2007;5:395-402.

63. Bayliss EA, Ellis JL, Steiner JF. Subjective assessments of comorbidity correlate with quality of life health outcomes: Initial validation of a comorbidity assessment instrument. Health Qual Life Outcomes. 2005;3:51.

64. Bayliss EA, Ellis JL, Steiner JF, Main DS. Initial validation of an instrument to identify barriers to self-management for persons with co-morbidities. Chronic illness. 2005;1:315-20.

65. Townsend A, Hunt K, Wyke S. Managing multiple morbidity in mid-life: a qualitative study of attitudes to drug use. BMJ. 2003;327:837.

66. Wolff JL, Roter DL. Hidden in plain sight: Medical visit companions as a resource for vulnerable older adults. Arch Intern Med. 2008;168:1409-15.

67. Gerteis M, Edgeman-Levitan S, Daley J. Through the patient's eyes. Understanding and promoting patient-centered care. San Francisco (CA): Jossey-Bass; 1993.

68. Bull SA, Hu XH, Hunkeler EM, Lee JY, Ming EE, Markson LE, Fireman B. Discontinuation of use and switching of antidepressants: influence of patientphysician communication. JAMA. 2002;288:1403-9. 
69. DiMatteo M. Social Suppor and patient adherence to medical treatment: a metaanalysis. Health Psychol. 2004;23:207-18.

70. Partnership for Solutions. Burden on family caregivers. Available from URL: http://www.partnershipforsolutions.org/problem/burden.html (Accessed 23 December 2010).

71. Partnership for Solutions. Survey reveals americans' concerns about living with chronic conditions and desire for elected officials to take action to improve care. Available from URL: http://www.partnershipforsolutions.org/statistics/ perceptions.html (Accessed 23 December 2010).

72. Travis SS, Kao HF, Acton GJ. Helping family members manage medication administration hassles. J Psychosoc Nurs Ment Health Serv. 2005;43:13-5.

73. Vickrey BG, Mittman BS, Connor KI, Pearson ML, Della Penna RD, Ganiats TG, et al. The effect of a disease management intervention on quality and outcomes of dementia care: a randomized, controlled trial. Ann Intern Med. 2006;145:713-26.

74. Campaign for Better Care. The case for better care. Available from URL: http:// www.nationalpartnership.org/site/DocServer/Fact_Sheet_1--The_Problem. pdf?docID=6202 (Accessed, 23 December 2010).

75. Institute for Patient- and Family-Centered Care. Advancing the practice of patient- and family- centered care how to get started... http://www.ipfcc.org/ pdf/getting_started.pdf (Accessed 11 February 2011)

76. Wolff JL, Roter DL. Family caregivers, patients, and physicians. J Gen Intern Med.25:487; author reply 488.

77. Boult C, Wieland GD. Comprehensive primary care for older patients with multiple chronic conditions: "Nobody rushes you through". JAMA.304:1936-43.

78. Boyd CM, Boult C, Shadmi E, Griswold M, Leff B, Brager R, et al. Guided care for multimorbid older adults. Gerontologist. 2007;47:697-704.

79. Creditor MC. Hazards of hospitalization of the elderly. Ann Intern Med. 1993;118:219-23.

80. Hohl CM, Dankoff J, Colacone A, Afilalo M. Polypharmacy, adverse drugrelated events, and potential adverse drug interactions in elderly patients presenting to an emergency department. Ann Emerg Med. 2001;38:666-71.

81. Librero J, Peiro S, Ordinana R. Chronic comorbidity and outcomes of hospital care: Length of stay, mortality, and readmission at 30 and 365 days. J Clin Epidemiol. 1999;52:171-9.

82. Spinewine A, Schmader KE, Barber N, Hughes C, Lapane KL, Swine C, Hanlon JT. Appropriate prescribing in elderly people: how well can it be measured and optimised? Lancet. 2007;370:173-84.

83. Tinetti ME, Baker DI, McAvay G, Claus EB, Garrett P, Gottschalk M, et al. A multifactorial intervention to reduce the risk of falling among elderly people living in the community. N Engl J Med. 1994;331:821-7.

84. Tinetti ME, Fried T. The end of the disease era. Am J Med. 2004;116:179-85.

85. Wagner EH, Austin BT, Von Korff M. Organizing care for patients with chronic illness. Milbank Q. 1996;74:511-44. 
86. Lucas GM, Chaudhry A, Hsu J, Woodson T, Lau B, Olsen Y, et al. Clinic-based treatment of opioid-dependent HIV-infected patients versus referral to an opioid treatment program: A randomized trial. Ann Intern Med.152:704-11.

87. Kinder LS, Katon WJ, Ludman E, et al. Improving depression care in patients with diabetes and multiple complications. J Gen Intern Med. 2006;21: 1036-41.

88. Katon W, Lin EH, Von Korff M, et al. Integrating depression and chronic disease care among patients with diabetes and/or coronary heart disease: the design of the TEAMcare study. Contemp Clin Trials.31: 312-322.

89. Bogner HR, de Vries HF. Integration of depression and hypertension treatment: a pilot, randomized controlled trial. Ann Fam Med. 2008;6: 295-301.

90. Vargas RB, Mangione CM, Asch S, Russo J, Simon G, Lin EH, et al. Can a chronic care model collaborative reduce heart disease risk in patients with diabetes? J Gen Intern Med. 2007;22: 215-222.

91. Lucas GM, Mullen BA, Weidle PJ, Hader S, McCaul ME, Moore RD. Directly administered antiretroviral therapy in methadone clinics is associated with improved HIV treatment outcomes, compared with outcomes among concurrent comparison groups. Clin Infect Dis. 2006;42:1628-35.

92. Boyd CM, Shadmi E, Conwell LJ, Griswold M, Leff B, Brager R, Sylvia M, Boult C. A pilot test of the effect of guided care on the quality of primary care experiences for multimorbid older adults. J Gen Intern Med. 2008;23:536-42.

93. Mead N, Bower P. Patient-centred consultations and outcomes in primary care: A review of the literature. Patient Educ Couns. 2002;48:51-61.

94. Stewart M, Brown J, Weston W, Freeman T. Patient-centred medicine: transforming the clinical method. 2nd ed. United Kingdom: Radcliffe Medical Press; 2003.

95. Yarnall KS, Pollak KI, Ostbye T, Krause KM, Michener JL. Primary care: Is there enough time for prevention? Am J Public Health. 2003;93:635-41.

96. Ostbye T, Yarnall KS, Krause KM, Pollak KI, Gradison M, Michener JL. Is there time for management of patients with chronic diseases in primary care? Ann Fam Med. 2005;3:209-14.

97. Grumbach K, Coffman J. Physicians and nonphysician clinicians: complements or competitors? JAMA. 1998;280:825-6.

98. Sommers LS, Marton KI, Barbaccia JC, Randolph J. Physician, nurse, and social worker collaboration in primary care for chronically ill seniors. Arch Intern Med. 2000;160:1825-33.

99. Archer SL, Greenlund KJ, Casper ML, Rith-Najarian S, Croft JB. Associations of community-based health education programs with food habits and cardiovascular disease risk factors among Native Americans with diabetes: The inter-tribal heart project, 1992 to 1994. J Am Diet Assoc. 2002;102:1132-5.

100. Vogeli C, Shields AE, Lee TA, Gibson TB, Marder WD, Weiss KB, Blumenthal D. Multiple chronic conditions: prevalence, health consequences, and implications for quality, care management, and costs. J Gen Intern Med. 2007;22Suppl3:391-5. 
101. Naylor M, Brooten D, Jones R, Lavizzo-Mourey R, Mezey M, Pauly M. Comprehensive discharge planning for the hospitalized elderly. A randomized clinical trial. Ann Intern Med. 1994;120:999-1006.

102. Naylor MD, Brooten D, Campbell R, Jacobsen BS, Mezey MD, Pauly MV, Schwartz JS. Comprehensive discharge planning and home follow-up of hospitalized elders: A randomized clinical trial. JAMA. 1999;281:613-20.

103. Naylor MD, McCauley KM. The effects of a discharge planning and home follow-up intervention on elders hospitalized with common medical and surgical cardiac conditions. J Cardiovasc Nurs. 1999;14:44-54.

104. Coleman EA, Grothaus LC, Sandhu N, Wagner EH. Chronic care clinics: A randomized controlled trial of a new model of primary care for frail older adults. J Am Geriatr Soc. 1999;47:775-83.

105. Coleman EA, Mahoney E, Parry C. Assessing the quality of preparation for posthospital care from the patient's perspective: The care transitions measure. Med Care. 2005;43:246-55.

106. Wieland D. The Program of All-Inclusive Care for the Elderly PACE. In: Schulz R NL, Rockwood K, Sprott R, (editors). The Encyclopedia of Aging $4^{\text {th }}$ ed. New York (NY): Springer: 2006. p.973-5.

107. Mookherjee S, Vidyarthi AR, Ranji SR, Maselli J, Wachter RM, Baron RB. Potential unintended consequences due to medicare's "no pay for errors rule"? A randomized controlled trial of an educational intervention with internal medicine residents. J Gen Intern Med.25:1097-101.

108. Wachter RM, Flanders SA, Fee C, Pronovost PJ. Public reporting of antibiotic timing in patients with pneumonia: Lessons from a flawed performance measure. Ann Intern Med. 2008;149:29-32.

109. Wachter RM, Foster NE, Dudley RA. Medicare's decision to withhold payment for hospital errors: The devil is in the details. Joint Commission Journal on Quality and Patient Safety / Joint Commission Resources. 2008;34:116-23.

110. Rosenthal MB, Frank RG. What is the empirical basis for paying for quality in health care? Med Care Res Rev. 2006;63:135-57.

111. Chaix-Couturier C, Durand-Zaleski I, Jolly D, Durieux P. Effects of financial incentives on medical practice: Results from a systematic review of the literature and methodological issues. Int J Qual Health Care. 2000;12:133-42.

112. Wolff JL, Roter DL, Given B, Gitlin LN. Optimizing patient and family involvement in geriatric home care. J Healthc Qual. 2009;31:24-33.

113. Mitnick S, Leffler C, Hood VL. Family caregivers, patients and physicians: Ethical guidance to optimize relationships. J Gen Intern Med. 25:255-60.

114. Soubhi H, Fortin M, Hudon C. Perceived conflict in the couple and chronic illness management: Preliminary analyses from the Quebec Health Survey. BMC Fam Pract. 2006; 7:59.

115. Scholle SH, Torda P, Peikes D, Han E, Genevro J. Engaging patients and families in the medical home. Rockville (MD): Agency for Healthcare Research and Quality; 2010.

116. Institute for Patient-Centered and Family-Centered Care. Available from URL: http://www.ipfcc.org/ (Accessed 27 April 2011). 
117. Boyd CM, Darer, J, Fried LP, Boult C, Wu AW. The challenges of following clincial practice guidelines in older patients with multiple comorbid conditions. J Am Geriatr Soc. 2003;51:S220.

118. Vitry AI, Zhang Y. Quality of Australian clinical guidelines and relevance to the care of older people with multiple comorbid conditions. Med J Aust. 2008;189:360-5.

119. Hunt SA, Baker DW, Chin MH, et al. ACC/AHA guidelines for the evaluation and management of chronic heart failure in the adult: A report of the American College of Cardiology/American Heart Association Task Force on Practice Guidelines (Committee to revise the 1995 Guidelines for the Evaluation and Management of Heart Failure). J Am Coll Cardiol. 2001;2005:1-56.

120. Recommendations for the medical management of osteoarthritis of the hip and knee: 2000 update. American College of Rheumatology Subcommittee on Osteoarthritis Guidelines. Arthritis Rheum. 2000;43:1905-15.

121. Brown AF, Mangione CM, Saliba D, Sarkisian CA. Guidelines for improving the care of the older person with diabetes mellitus. J Am Geriatr Soc. 2003;51:S265-80.

122. Kent DM, Hayward RA. Limitations of applying summary results of clinical trials to individual patients: The need for risk stratification. JAMA. 2007;298:1209-12.

123. Kent DM, Kitsios G. Against pragmatism: on efficacy, effectiveness and the real world. Trials. 2009;10:48.

124. Fabbri L, Boyd CM, Boschetto P, et al. How to deal with multiple comorbidities in guideline development: An official ATS/ERS Workshop Report. Manuscript submitted for publication. 2010.

125. Boyd C. AHRQ R21 Improving Clinical Practice Guidelines for Complex Patients. Agency for Healthcare Research and Quality.

126. Werner RM, Greenfield S, Fung C, Turner BJ. Measuring quality of care in patients with multiple clinical conditions: Summary of a conference conducted by the Society of General Internal Medicine. J Gen Intern Med. 2007;22:1206-11.

127. Higashi T, Wenger NS, Adams JL, Fung C, Roland M, McGlynn EA, et al. Relationship between number of medical conditions and quality of care. $\mathrm{N}$ Engl J Med. 2007;356:2496-504.

128. Shadmi E, Boyd CM, Hsiao CJ, Sylvia M, Schuster AB, Boult C. Morbidity and older persons' perceptions of the quality of their primary care. J Am Geriatr Soc. 2006;54:330-4.

129. Min LC, Wenger NS, Fung C, Chang JT, Ganz DA, Higashi T, et al. Multimorbidity is associated with better quality of care among vulnerable elders. Med Care. 2007;45:480-8.

130. Chang JT, Hays RD, Shekelle PG, MacLean CH, Solomon DH, Reuben DB, et al. Patients' global ratings of their health care are not associated with the technical quality of their care. Ann Intern Med. 2006;144:665-72.

131. Fung CH, Setodji CM, Kung FY, Keesey J, Asch SM, Adams J, McGlynn EA. The relationship between multimorbidity and patients' ratings of communication. J Gen Intern Med. 2008;23:788-93. 
132. National Quality Forum. Multiple Chronic Conditions Measurement Framework. Available from URL: http://www.qualityforum.org/Projects/ Multiple_Chronic_Conditions_Measurement_Framework.aspx (Accessed 27 April 2011).

133. Institute of Medicine. Crossing the quality chasm: A new health system for the 21st century. Washington (DC): National Academy Press; 2001.

134. Ganz DA, Wenger NS, Roth CP, Kamberg CJ, Chang JT, MacLean CH, et al. The effect of a quality improvement initiative on the quality of other aspects of health care: the law of unintended consequences? Med Care. 2007;45:8-18.

135. Wenger NS, Solomon DH, Roth CP, MacLean CH, Saliba D, Kamberg CJ, et al. The quality of medical care provided to vulnerable community-dwelling older patients. Ann Intern Med. 2003;139:740-7.

136. Pham HH, Schrag D, O'Malley AS, Wu B, Bach PB. Care patterns in Medicare and their implications for pay for performance. N Engl J Med. 2007;356:1130-9.

137. Boyd CM, Boult C, Shadmi E, Leff B, Brager R, Dunbar L, et al. Guided Care for Multimorbid Older Adults. Gerontologist. 2007;47:697-704.

138. Counsell SR, Callahan CM, Buttar AB, Clark DO, Frank KI. Geriatric Resources for Assessment and Care of Elders (GRACE): A new model of primary care for low-income seniors. J Am Geriatr Soc. 2006;54:1136-41.

139. Counsell SR, Callahan CM, Clark DO, Tu W, Buttar AB, Stump TE, Ricketts GD. Geriatric care management for low-income seniors: A randomized controlled trial. JAMA. 2007;298:2623-33.

140. Freund T, Kayling F, Miksch A, Szecsenyi J, Wensing M. Effectiveness and efficiency of primary care based case management for chronic diseases: rationale and design of a systematic review and meta-analysis of randomized and non-randomized trials. BMC Health Serv Res.10:112.

141. Freund T, Wensing M, Mahler C, Gensichen J, Erler A, Beyer M, et al. Development of a primary care-based complex care management intervention for chronically ill patients at high risk for hospitalization: a study protocol. Implement Sci.5:70.

142. Soubhi H, Bayliss EA, Fortin M, Hudon C, van den Akker M, Thivierge R, et al. Learning and caring in communities of practice: using relationships and collective learning to improve primary care for patients with multimorbidity. Ann Fam Med.8:170-7.

143. Boult C, Green AF, Boult LB, Pacala JT, Snyder C, Leff B. Successful models of comprehensive care for older adults with chronic conditions: evidence for the Institute of Medicine's "retooling for an aging America" report. J Am Geriatr Soc. 2009;57:2328-37. 